\title{
THE HIGH-HEAT FLUX TESTING OF AN INTERCEPTIVE DEVICE FOR AN INTENSE PROTON BEAM ${ }^{1}$
}

\author{
Robert Valdiviez, Dinh Nguyen, Larry Earley, Richard LaFave, Felix Martinez, Armando Rendon \\ Los Alamos National Laboratory
}

\begin{abstract}
An interceptive device referred to here as a scraper has been designed and tested for use in a diagnostic device [1]. The scraper will be used to probe a proton beam in order to detect the formation of beam halo [2]. Probing the proton beam exposes the scraper to high heat fluxes on the order of $610 \mathrm{~kW} / \mathrm{cm}^{2}$. The high-heat flux exposure is cyclic since the beam is probed while in pulsed mode. In order to test the design repetitive high-heat flux testing has been performed on a prototype design of the scraper. This paper describes the design, analysis, and testing of the scraper.
\end{abstract}

\section{INTRODUCTION}

Figure 1 depicts the scraper design. Figure 2 is a picture of a scraper installed in a diagnostic assembly [3]. The scraper consists of a copper base with a water cooling channel on one a side, and a graphite protective face. The scraper is $3.2 \mathrm{~cm}$ on side, and is $3.0 \mathrm{~mm}$ thick. The graphite protective face is $1.5 \mathrm{~mm}$ thick, and is joined to the copper base by brazing the two together. The graphite material is type AXF-5Q [4]. Two different alloys have been used to braze the copper and graphite together, TiCuSil ( $4.5 \%$ Titanium, $26.7 \%$ Copper, $68.8 \%$ Silver) and TiCuNi ( $70 \%$ Titanium, $15 \%$ Copper, $15 \%$ Nickel) [5].

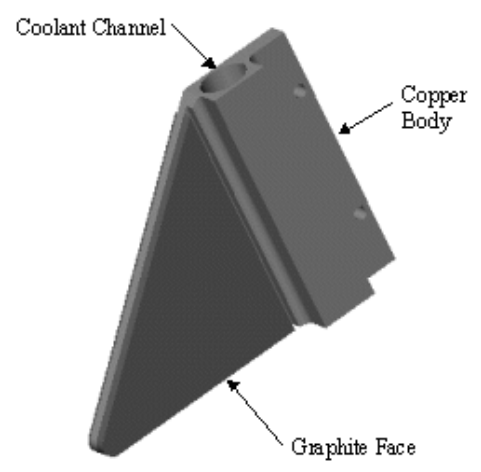

Figure 1: Halo Scraper

\section{SCRAPER ANALYSIS AND DESIGN}

Finite-element and finite-difference models of the scraper design have been created in order to predict the thermal and structural response of the scraper. The peak temperatures and stresses have been predicted in order to set the details of the scraper design.

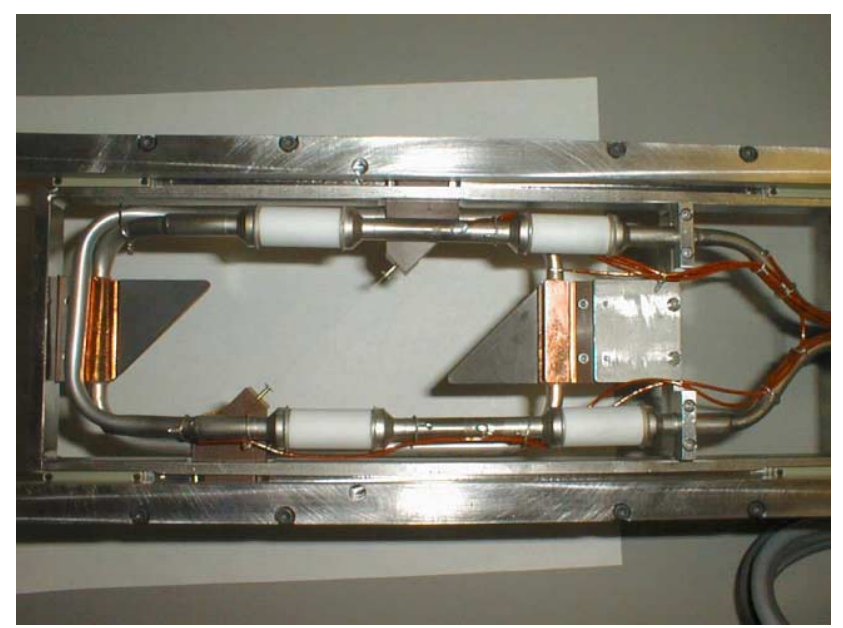

Figure 2: Halo Assembly with Scrapers \& 33 micron diameter Wire Installed

The finite-difference models were used primarily to study the predicted peak temperatures for a given scraper design. The beam parameters could be incorporated easily into these models, and the model analyzed in a short amount of time to determine if a proposed design could be viable. Various types of graphite were modeled, along with various configurations of the scraper.

The finite-element model was used to analyze the detailed scraper design. A transient thermal analysis was performed first to predict the pseudo-steady state thermal profile of the scraper being exposed to the proton beam. This model predicted that the intercepting graphite face could be kept well below the limiting temperature of $2205{ }^{\circ} \mathrm{C}$. Near $2205{ }^{\circ} \mathrm{C}$ the graphite structural properties begin to degrade significantly. The analysis revealed that the peak graphite surface temperature is dependent mainly on the beam parameters of current density and repetition rate. The cooling water flow does not affect the graphite peak temperature strongly because the graphite itself is a significant thermal resistance that is placed in between the heat load and the coolant channel. The coolant channel flow accommodates the thermal management of the scraper by removing the residual thermal power through advection. The predicted thermal profile was used to predict the peak stresses for the case of beam-on and beam-off. The peak stresses were evaluated, as well as

\footnotetext{
${ }^{1}$ This work sponsored by the U.S. Department of Energy
} 
the cycling between minimum and maximum stress levels for fatigue considerations. Principal stresses were analyzed for the graphite, and Von Mises stresses were analyzed for the copper. In both cases a good margin was predicted between the induced stresses and the material's capability.

The peak graphite temperature was predicted to be $493{ }^{\circ} \mathrm{C}$. The predicted peak copper body temperature was predicted to be about $85^{\circ} \mathrm{C}$. The coolant channel has a water flow rate of 3.78 liters $/ \mathrm{min}$, and undergoes a temperature rise of less than $0.7^{\circ} \mathrm{C}$. The proton beam may be pulsed on and off up to a rate of $6 \mathrm{~Hz}$. The thermal model predicts that the braze joint does not fluctuate in temperature. The induced stress around the braze joint does fluctuate due to the graphite expanding and contracting due to the beam's pulsing thermal load. The braze joint does experience a fatigue load in the immediate vicinity of the beam interaction region due to the thermal expansion and contraction of the protective graphite face. The peak principal stress in the graphite was predicted to be $31 \mathrm{MPa}$ in compression. The graphite has a compressive strength of $138 \mathrm{MPa}$. The peak Von Mises stress in the copper behind the beam interaction region was predicted to be $3.4 \mathrm{MPa}$. OFE copper has a yield strength of $48 \mathrm{MPa}$ after annealing.

\section{AFEL TESTING CONFIGURATION}

The Advanced Free Electron Laser (AFEL) facility [6] is designed primarily to produce laser light by wiggling an electron beam and employing regenerative optics feedback. This testing effort used the electron beam after it had passed through the wiggler magnet section. A test section for the scraper prototypes was installed in the down-stream beam tube, immediately up stream from the beam dump. The test configuration can be seen in Figure 3. Figure 4 is a view of the scraper test assembly. The vacuum cube section housed the scraper being tested. The up-stream and down-stream tee sections housed phosphor screens for imaging the beam. The screens were mounted on actuators to enable moving them into and out of the beam.

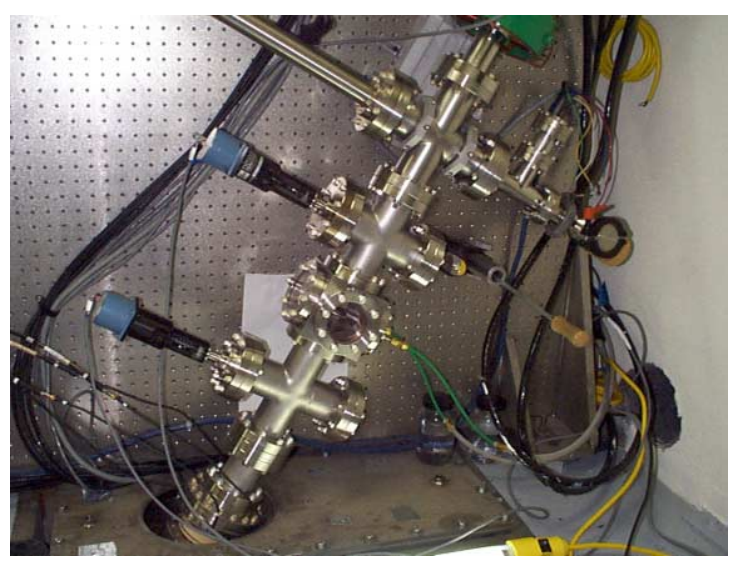

Figure 3: AFEL Scraper Test Configuration

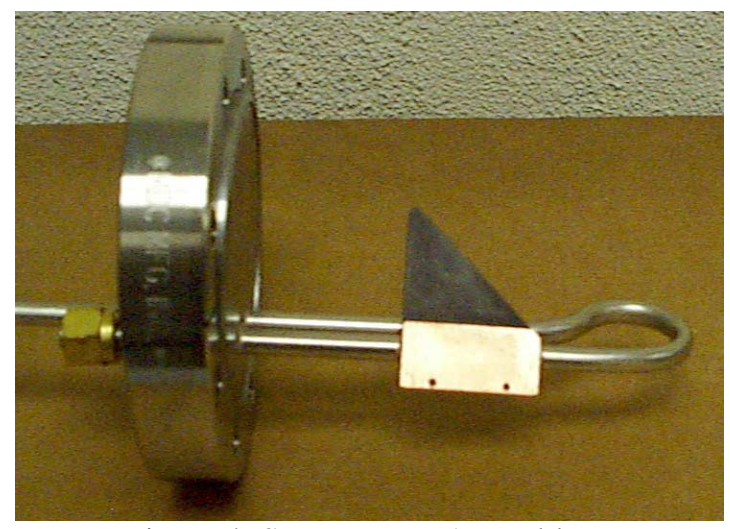

Figure 4: Scraper Test Assembly

The scraper testing utilized the beam parameters of a charge over the range of 1.5 to $3.0 \mathrm{nC}, 950$ micropulses in 9 microseconds, a beam spot size of $1.3 \mathrm{~cm}^{2}$ or less, and a beam repetition rate of $5 \mathrm{~Hz}$. Using a beam spot size of $1.3 \mathrm{~cm}^{2}$ or less ensured that a minimum heat flux of $610 \mathrm{~kW} / \mathrm{cm}^{2}$ would be placed on the scraper face. The beam was focused using a triplet magnet set located immediately up-stream from the scraper test section. The large turning magnet at the outlet of the wiggler magnet section and a small dipole magnet were used to steer the beam in the test section.

\section{SCRAPER HIGH-HEAT FLUX TESTING}

The primary aspect investigated with the high-heat flux testing was the scraper design's ability to withstand fatigue loading. The developed thermal profiles of the scraper in the testing and actual application are different, yet are similar enough to investigate the design's ability to withstand fatigue loading. The stopping powers of graphite and copper are listed in Table 1. The halo experiments are conducted on a $6.7 \mathrm{MeV}$ proton beam, and the scraper high heat flux testing was conducted using a $16.5 \mathrm{MeV}$ electron beam. Equation 1 is used to calculate the amount of power that is deposited per beam macropulse for either beam case.

\begin{tabular}{|c|c|c|}
\hline Material & $\begin{array}{l}\text { Stopping Power } \\
\left(\mathrm{MeV}-\mathrm{cm}^{2} / \mathbf{g m}\right)\end{array}$ & $\begin{array}{l}\text { Stopping Power } \\
\left(\mathrm{MeV}-\mathrm{cm}^{2} / \mathbf{g m}\right)\end{array}$ \\
\hline & 6.7-MeV proton [7] & 16.5-MeV electron [8] \\
\hline Graphite & 99.1 & $\sim 2.08$ \\
\hline Copper & ---- & $\sim 2.51$ \\
\hline
\end{tabular}

Table 1: Material Stopping Powers

$$
\mathbf{Q}=\mathbf{P}_{\text {stop }} * \boldsymbol{\rho} * \text { Thick } * \mathbf{I}_{\text {beam }}
$$

\footnotetext{
Where: $\mathbf{Q}$ - Thermal power in watts

$\mathbf{P}_{\text {stop }}$ - Material stopping power, $\mathrm{eV}-\mathrm{cm}^{2} / \mathrm{gm}$

$\boldsymbol{\rho}$ - Material density, $\mathrm{gm} / \mathrm{cm}^{3}$

Thick - Material thickness, $\mathrm{cm}$

$\mathbf{I}_{\text {beam }}$ - Beam current, amps
} 
The different graphite stopping power values for protons and electrons lead to the fact that the proton beam is stopped in the first $0.3 \mathrm{~mm}$ of the graphite thickness, whereas the electron beam penetrates the entire scraper thickness. This creates a different thermal condition between the actual application and the test for the scraper. In the case of the proton beam the heat load is very close to being a surface heat flux on the face of the graphite since the penetration depth is very small. In the case of the electron beam the thermal load is similar to an internal heat generation load since the beam energy is partially attenuated over the whole thickness of the scraper, the graphite and the copper base. Since the scraper is a thin member, the difference in the thermal loading between the two beam cases is not too significant. The thermal profiles developed in the scraper for each case are similar enough for testing purposes. The ability to cycle the thermal load at a frequency close to the desired application for the scraper is more important than to match the thermal and stress profiles exactly. Since the temperature of the braze joint does not oscillate in the proton beam case and it does oscillate for the electron beam test case, the braze joint experiences a more punishing cyclic thermal loading in the electron beam testing condition. The test case envelopes the actual application in this respect.

\section{TESTING RESULTS}

Two series of tests were conducted in the AFEL. The first series tested the scraper design using TiCuSil as the braze alloy between the graphite face and the copper base. The second series tested the scraper design using TiCuNi as the braze alloy to join the graphite and copper. The results of both tests revealed that the scraper design is capable of withstanding the halo experiment environment without suffering damage.

The TiCuSil alloy scraper test was conducted for a total of 180,000 cycles. The scraper was exposed to a heat flux of approximately $610 \mathrm{~kW} / \mathrm{cm}^{2}$ for 144,000 cycles. The last 36,000 cycles were conducted at a heat flux of approximately $1.02 \mathrm{MW} / \mathrm{cm}^{2}$. Since the scraper had survived the first 144,000 cycles, or 8 hours of testing without any visible damage it was decided to increase the heat flux on the scraper by using the maximum charge available from the photocathode at the source end of the AFEL linac. The final 2 hours of testing were conducted at this heat flux that is $67 \%$ greater than the design heat flux. No visible damage occurred to the scraper. The testing at the heat flux of $1.02 \mathrm{MW} / \mathrm{cm}^{2}$ was performed in order to begin investigating the possibility of inserting the scraper deeper into the proton beam than the planned location of $2 \mathrm{rms}$ widths from center.

The TiCuNi alloy scraper test was conducted for a total of 162,000 cycles. Of the total testing 126,000 cycles, or 7 hours was conducted at a heat flux of approximately $610 \mathrm{~kW} / \mathrm{cm}^{2}$. The last 36,000 cycles, or 2 hours were conducted at a lower varying heat flux due to the charge from the photocathode rising and falling over a range with time. The drive laser alignment for the linac source was drifting due to laser room cooling problems, and the photocathode was likely near the end of its service life. This scraper test had completed over half of its intended cycles of 180,000 at the design heat flux, so it was decided to end the testing at this point.

The testing proved the scraper design to be acceptable for use in the halo measuring diagnostic assembly. Either alloy could be used for fabrication since each test was successful. Success was measured by the fact that no visible damage occurred to the scraper as a result of the thermally induced fatigue loading. The TiCuSil alloy is the first choice for use in fabrication because it has a few advantages over the TiCuNi alloy. Two advantages are that the TiCuSil is not magnetic and it brazes at a lower temperature than the $\mathrm{TiCuNi}$.

\section{CONCLUSIONS}

The high-heat flux testing performed on the prototype scrapers revealed that the design can withstand the service environment of the halo-measuring diagnostic device. The thermally induced fatigue loading can be withstood by the scraper with no visible damage such as separation of the graphite and copper, or cracking of the materials.

At the time of the submission of this paper the scrapers on the halo-measuring diagnostic with the most accumulated measuring cycles had no visible damage. The peak heat flux that these scrapers have experienced in actual service is approximately $600 \mathrm{~kW} / \mathrm{cm}^{2}$.

\section{REFERENCES}

[1]R. Valdiviez, "Intense Proton Core and Halo Beam Profile Measurement: Beam Line Component Mechanical Design“, LINAC 2000, Monterey, CA, August 2000.

[2]T. Wangler, "Beam Halo in Proton Linac Beams", LINAC 2000, Monterey, CA, August 2000.

[3]R. Valdiviez, "The Final Mechanical Design, Fabrication, and Commissioning of a Wire Scanner and Scraper Assembly for ...", these proceedings.

[4]Type AXF-5Q graphite is produced by Poco Specialty Materials, Decatur, TX.

[5]TiCuSil and TuCuNi brazing alloys are produced by Wesgo Metals, San Carlos, CA.

[6]Nguyen, D. C., et. al., "First Lasing of the Regenerative Amplifier FEL", Nuclear Instruments and Methods in Physics Research A 429, Elsevier Science Publishing, 1999.

[7]W. Barkas, M. Berger, "Table of Energy Losses and Ranges of Heavy Charged Particles", NASA, 1964.

[8]National Academy of Sciences, "Studies in Penetration of Charged Particles in Matter", Report Number 39, 1964. 